\title{
Roberts Bartholow: the progenitor of human cortical stimulation and his contentious experiment
}

\author{
Devi P. Patra, MD, MCh, MRCSEd, ${ }^{1,5,6}$ Ryan A. Hess, BSE, ${ }^{1,5,6}$ Karl R. Abi-Aad, MD, ${ }^{1,5,6}$ \\ Iryna M. Muzyka, MD, ${ }^{4}$ and Bernard R. Bendok, MD, MSCI1-3,5,6
}

Departments of ${ }^{1}$ Neurological Surgery, ${ }^{2}$ Otolaryngology, ${ }^{3}$ Radiology, and ${ }^{4}$ Neurology, ${ }^{5}$ Precision Neuro-therapeutics Innovation Lab, and ${ }^{6}$ Neurosurgery Simulation and Innovation Lab, Mayo Clinic, Phoenix, Arizona

\begin{abstract}
Roberts Bartholow, a physician, born and raised in Maryland, was a surgeon and Professor in Medicine who had previously served the Union during the Civil War. His interest in scientific research drove him to perform the first experiment that tested the excitability of the human brain cortex. His historical experiment on one of his patients, Mary Rafferty, with a cancerous ulcer on the skull, was one of his great accomplishments. His inference from this experiment and proposed scientific theory of cortical excitation and localization in humans was one of the most critically acclaimed topics in the medical community, which attracted the highest commendation for the unique discovery as well as criticism for possible ethical violations. Despite that criticism, his theory and methods of cortical localization are the cornerstone of modern brain mapping and have, in turn, led to countless medical innovations.
\end{abstract}

https://thejns.org/doi/abs/10.3171/2019.6.FOCUS19349

KEYWORDS Roberts Bartholow; human cortical mapping; brain localization; Mary Rafferty; cortical excitability; history of brain mapping

\begin{abstract}
Perhaps a corpse would be reanimated; galvanism had given tokens of such things: perhaps the component parts of a creature might be manufactured, brought together and endued with vital warmth.
\end{abstract}

- Mary Shelley, 1818

Frankenstein or The Modern Prometheus

The more we attempt to decode the human brain, the more mysterious it proves to be. Modern technology has revolutionized the fidelity and effortlessness of human brain mapping, and its importance in current practice is ineffable. The science of brain localization is just as fascinating as its history. The concepts of brain function localization with direct cortical mapping are essentially the same as those described by our forerunners in their phenomenal experiments centuries ago. ${ }^{41,43}$ The foundation of cortical stimulation started with the understanding of neural transmission and from the awareness of its electrical nature. In 1802, Giovanni Aldini, who was the nephew of Galvani, used galvanic current in dismembered human corpses for demonstration of muscular contraction. ${ }^{1}$ Those "horrible facial grimaces" from cortical surface electrification formed the earliest demonstration of electrical excitability of the human brain. Subsequently, electrical stimula- tion of "living" animals was attempted by Luigi Rolando in 1809 and by Hitzig and Fritsch in 1870.34,42 However, it was in the late 19th century when functional mapping of the brain was demonstrated, when David Ferrier made his revolutionary contribution of sensory and motor cortex mapping in a variety of species, published in his book The Functions of the Brain (Fig. 1). ${ }^{29}$ Inspired by these great discoveries, Roberts Bartholow (1831-1904) performed his timeless experiment with direct cortical stimulation in one of his patients and established the historical footprint of human brain mapping.

\section{Bartholow: Early Life}

Roberts Bartholow was born in New Windsor, Maryland, in November 1831 (Fig. 2). ${ }^{37} \mathrm{He}$ was described as having no close friends or associates and being a force to be reckoned with in arguments, both due to his reserved, analytical, and mercilessly sarcastic nature. He excelled academically throughout his life, with notable accomplishments beginning at Calvert College. ${ }^{36} \mathrm{He}$ received a Master of Arts in 1848, before studying medicine at the University of Maryland and receiving his degree in $1852 .^{30}$ After a few years working as a private practitioner in Bal- 

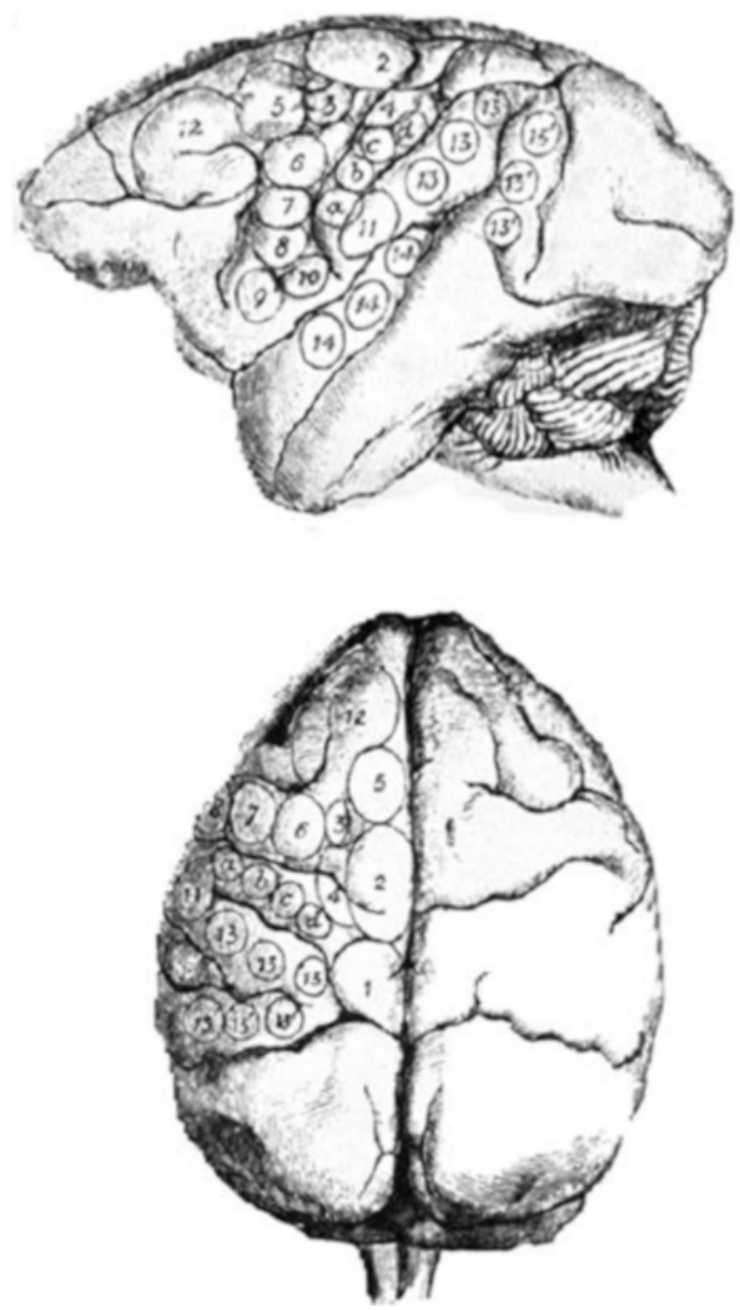

FIG. 1. Ferrier's early results of cortical mapping in a monkey brain. Reproduced from Ferrier D: The Functions of the Brain. London: Smith, Elder, \& Co., 1886. Public domain.

timore, he decided to join the US army, where his medical career continued (Fig. 3). He was one of very few selected to serve as an assistant surgeon and served in a number of army medical posts with loyalty to the Union during the early years of the Civil War. ${ }^{35}$ He married Maria Walker in 1862, the same year that he published A Manual of Instructions for Enlisting and Discharging Soldiers with the Medical Examination of Recruits, which became the government's official handbook on the subject..$^{10} \mathrm{He}$ and Maria Walker had two children, and he left the army in 1864 following their births.

Following his service in the army, Bartholow devoted his life to the study and practice of medicine. He taught in Cincinnati as Professor of Medical Chemistry at the Medical College of Ohio and joined the staff of Good Samaritan Hospital in 1866. He continued to be remarkably productive in the teaching and practice of medicine, publishing a number of books on various subjects while living in Cincinnati. ${ }^{9}, 12,14,16$ In 1869 he was named Professor of Materia Medica and Therapeutics, as well as Professor of

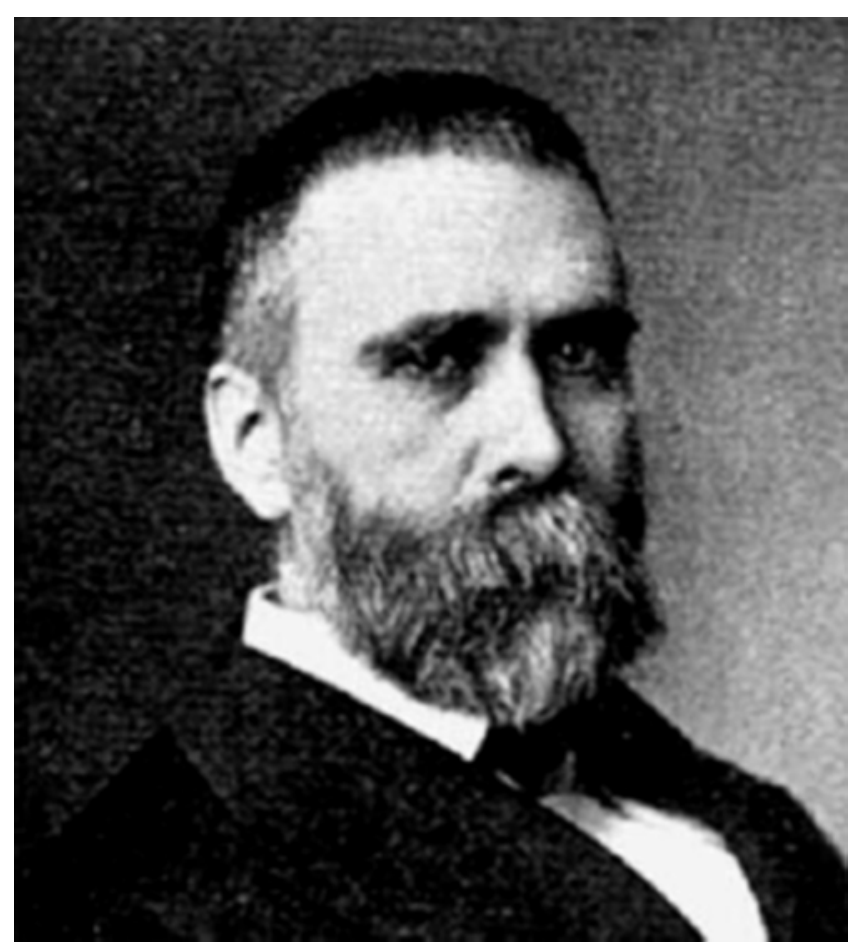

FIG. 2. Undated photograph of Roberts Bartholow. Reproduced from Juettner O: Daniel Drake and His Followers: Historical and Biographical Sketches. Cincinnati: Harvey Publishing Co., 1909. Public domain.

Clinical Medicine at the Medical College of Ohio. In 1874, he was appointed Professor of the Theory and Practice of Medicine at the same institution. Throughout this time, he was engaged in peripheral pursuits to his practice and teaching, including active membership in the Cincinnati Academy of Medicine and founding The Clinic, a weekly medical journal. Contrary to many of his peers, Bartholow was a proponent of basing clinical decisions in the basic sciences and laboratory research rather than on bedside experiences alone. ${ }^{19}$ This focus was likely a driving force behind his laboratory research on animals and his experiment on human cortical stimulation.

\section{Mary Rafferty}

The unfortunate yet famous patient of Bartholow and the subject of his notable experiment was a 30 -year-old Irish woman named Mary Rafferty, who likely immigrated to the US during times of famine in Ireland. Her description is largely limited to that which was reported by Bartholow, as few other accounts of her exist and most of these other accounts were based on Bartholow's records. ${ }^{8}$ According to Bartholow, she was working as a domestic in Cincinnati. However, in another report by Kuntz in 1970, she was mentioned as the servant in Bartholow's household, although the authenticity of this relationship is unknown. ${ }^{30,33}$ Her misery had started in infancy, when she had "fallen into fire" and burned her hair, with the subsequent hair loss compelling her to wear wigs. Almost after 3 decades in 1872, she developed a nonhealing ul- 


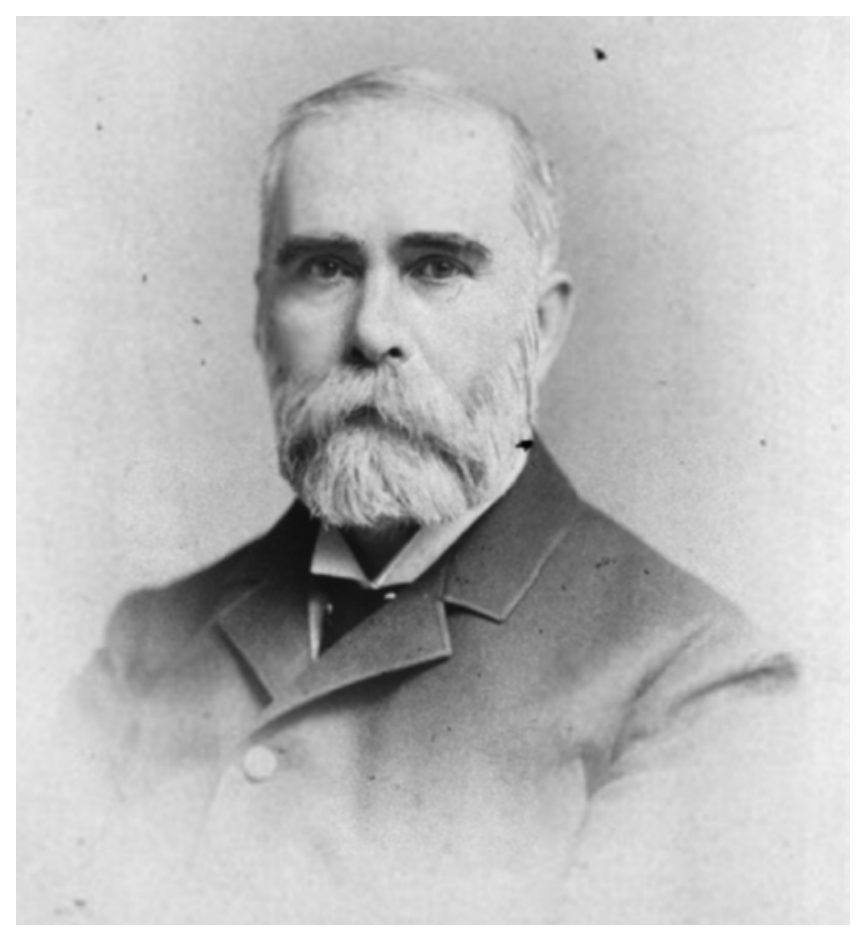

FIG. 3. Undated photograph of Roberts Bartholow. National Library of Medicine Image ID No. B02414, courtesy of the U.S. National Library of Medicine. Retrieved from https://collections.nlm.nih.gov/catalog/nlm: nlmuid-101409951-img. Public domain.

cer that she initially attributed to irritation from the wigs. However, the ulcer woefully progressed to a significant extent within a year. At the time of her admission in 1874 just prior to when Bartholow performed his experiment, she had an extensive lesion that was described as "epithelioma" involving her skull in the parietal region. In his report, Bartholow had quite precisely described the location of the lesion to be 4 inches from the root of the nose, posteriorly extending to 2.25 inches from occiput and 4 inches from the left external auditory meatus. His original description also included the drawing of the head (Fig. 4) and the position of the ulcer. Specific to the ulcer description, he reported "the skull itself eroded and has disappeared over a space two inches in diameter, where the pulsations of the brain are plainly seen...the excavation secretes a great quantity of pus; pain is experienced, but it is not very acute." There was perhaps deep excavation of the brain tissue from injury or drainage of pus at the depth of the ulcer, but this was not clear from Bartholow's report. With such a critical condition, Rafferty was considered "hopelessly diseased" with "early extinction of life" imminently threatening her as a result. ${ }^{5,7}$ Exploring the situation, Bartholow looked forward to an opportunity for his cortical stimulation experiment involving passing some insulated needles into the brain substance. Understandably, he (probably) considered this procedure almost painless and low-risk, although he may have expected to cause some pain based on Ferrier's reports on animals. ${ }^{28}$ Finally, Rafferty, the "cheerful lady," consented to the historic live human experimentation.

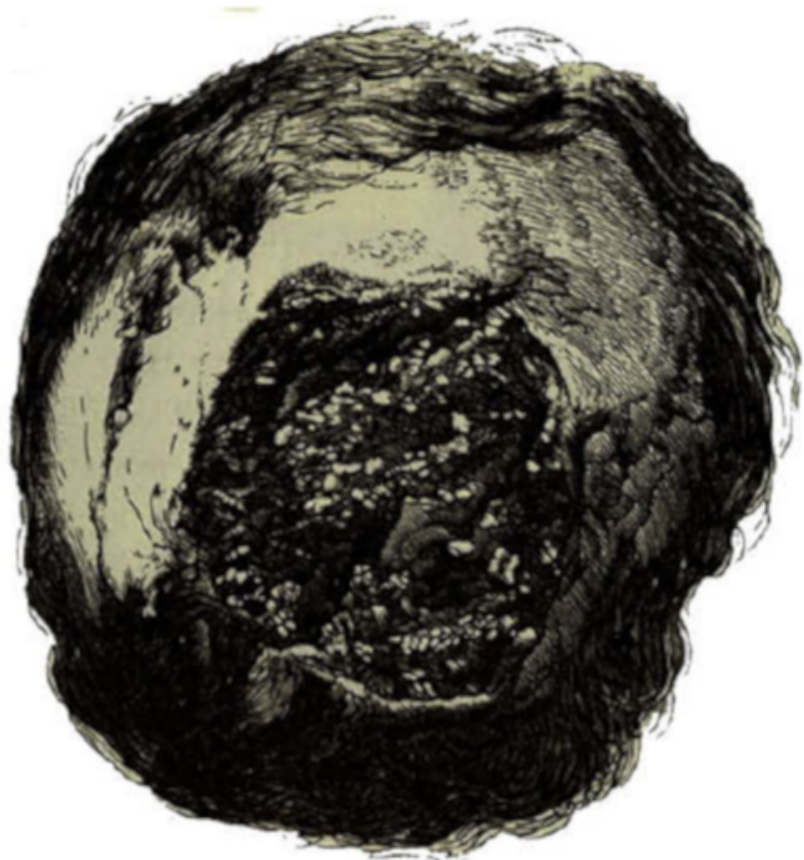

FIG. 4. Illustration of Rafferty's ulceration and exposed tissue. Reproduced from Bartholow R: Experimental investigations into the functions of the human brain. Am J Med Sci 66:305-313, 1874. Public domain.

\section{The Experiment}

At the time of Bartholow's experiment, the scientific community was divided on whether or not the cortex was electrically excitable. Prior work by Ferrier as well as Fritsch and Hitzig on animals suggested that it was, while publications from numerous others displayed inexcitability of the cortex..$^{30}$ Therefore, a number of questions remained that Bartholow hoped to answer in his experiment. He hoped to explore whether or not the cortex was excitable in humans, specifically the posterior cortex, which was exposed by Rafferty's ulceration. This included exploration using both galvanic (direct) and faradic (alternating) currents at different strengths. Additionally, he hoped to determine how stimulation of each hemisphere would affect results given prior knowledge of functional symmetry and contralateral control. The differences in excitability of both the dura and the cortex were to be investigated, as well as the generalizability of the human brain to animal brains where cortical excitability affecting different regions and functions had previously been demonstrated. If the cortical stimulation proved to create a physiological effect, Bartholow hoped to measure sphygmometric and thermometric outcomes. Finally, the overall purpose of the experiment was to make discoveries that would eventually lead to diagnostic and therapeutic applications. This was all to be investigated using equipment that was not well described in Bartholow's report. The "electrical room" used for electrotherapy at Good Samaritan Hospital was the site of the experiment, and was outfitted with a number of apparatuses used to generate and control current that was applied to patients. ${ }^{4,6}$ This included faradic currents generated by induction or double-cup batteries and 

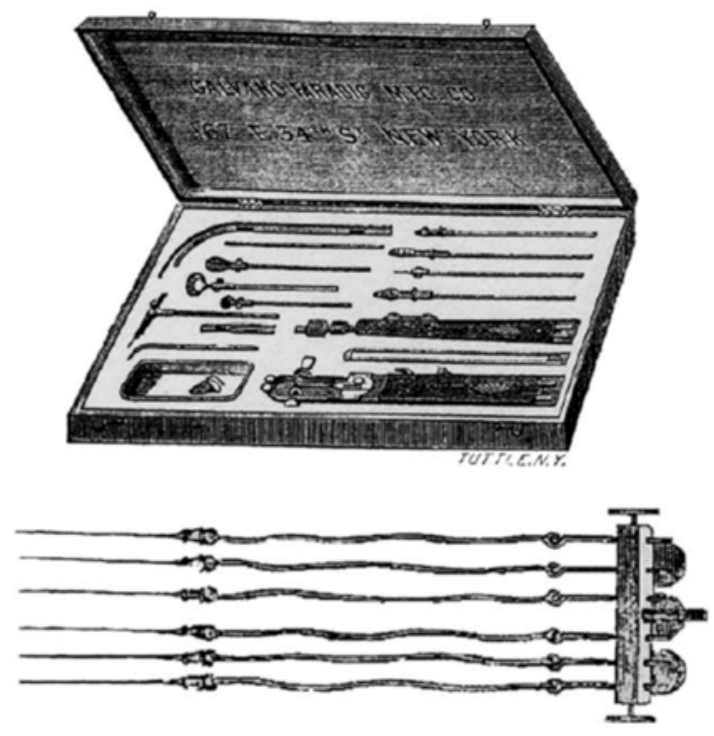

FIG. 5. Illustration of needle electrodes and other equipment used in the electrical room of Good Samaritan Hospital. Reproduced from Bartholow R: The electrical room of the Good Samaritan Hospital. Clinic (Paris) 2:86-89, 1872. Public domain.

galvanic currents generated by a 60-cup battery, which allowed the user to turn the current on or off and select the amount of voltage to be applied. The administration of electricity was performed through "needle electrodes of various lengths" that were "insulated to near their points" for semiprecise localization (Fig. 5). Other than the chair that Rafferty lay in, there was little to no description of other equipment used, such as temperature or pressure monitoring devices.

The experiment consisted of a number of different trial components (referred to as "observations" by Bartholow) aimed at elucidating answers to the variety of questions that gave rise to it. It was conducted over a number of days under the supervision of Dr. Steeley, the house physician of Good Samaritan at the time. The interventions performed on the 1st day and the observed results of each are summarized in Table 1. No tests were attempted on the 2nd day of the experiment. On the 3rd day of the experiment, Rafferty returned to the electrical room for what was intended to be the first tests using galvanic current. However, Rafferty's condition had deteriorated significantly, and she reportedly appeared pale and depressed with blue lips. She had difficulty in walking with complaints of extreme dizziness and right-sided numbness and tingling. Physical examination revealed right-sided paresis and rigidity followed by rhythmic contraction and relaxation of the right side. Rafferty was placed in the recumbent position while barely conscious, at which point inhaled chloroform was administered, causing the rhythmic movements to stop. On the 4th day of the experiment, Bartholow did not attempt any tests and simply reported, "Mary was decidedly worse, she remained in bed, was stupid and incoherent." Additionally, later that night, Mary experienced a right-sided convulsive seizure for 5 minutes followed by unconsciousness and complete right-sided paralysis with noxious stimulus producing no movement response. Bartholow ended his report following this encounter before Rafferty died at an unspecified time with no other details provided. ${ }^{5}$

Following the results of the experiment, Bartholow reported Rafferty's autopsy results after likely performing it himself. He was particularly interested in the brain and any morphological changes that may provide further insights into the results of the experiment. He reported grossly that superficial veins appeared "deeply engorged," a "thick layer" of pus covering the entire left hemisphere, an "intense degree" of vascularity throughout the brain, and a "thick layer of greenish-white exudation" over the portion of the brain that the ulcer covered. He also reported a lack of changes or abnormalities at the superficial sites of needle insertion. Following gross inspection, Bartholow reported that the brain was fixed using the standard procedure at the time for 24 hours. The brain was then sectioned the next day, presumably in such a way that the needle tracks could be seen, although details of the sectioning procedure are lacking. It was reported that along each needle track was "a line of diffluent white matter," indicative of pathological changes resulting from insertion of each needle. Although agreement on definitions of cerebral anatomy was lacking at the time of the experiment, it can be deduced that the needles inserted into the substance of the brain penetrated roughly $1-1.5$ inches into the posterior parietal lobe, approaching the corpus callosum. ${ }^{5}$

Bartholow's experiment unveiled quite a bit of information regarding cortical excitability and the functions of the brain that were previously unknown during a time that the topic was one of active debate. The echoes of these findings are heard to this day, nearly a century and a half later, through the integration of the principles of cortical excitability into diagnostic and therapeutic neuroscience. Perhaps Bartholow foresaw this grand impact or the heated disagreements that would shortly follow his experiment, because he let his observations speak for themselves in his text. Refraining from interpreting any findings, he ended his report briefly with the statement, "It has seemed to me most desirable to present the facts as I observed them, without comment." In April of 1874, Bartholow published "Experimental investigations into the functions of the human brain" in the 66th volume of the American Journal of the Medical Sciences, ${ }^{5}$ reigniting the controversy surrounding the topic that had lingered within the scientific community.

\section{Perceptions of the Experiment}

The earliest reactions to the report came shortly after its original publication, with the first appearing in the same issue. A staff writer for the journal cited it while reviewing work by Hermann Nothnagel, who had shown convulsive movements in rabbits following insertion of microscopic needles into their brains, saying this work was supportive of Bartholow's findings. ${ }^{39}$ Ferrier, whose similar work in animals had inspired Bartholow, was the next to cite the paper the following month in a report published in The London Medical Record. ${ }^{27}$ He noted the difference 
TABLE 1. Trials and observed results conducted on day 1 of Bartholow's experiment

\begin{tabular}{|c|c|c|}
\hline Observation and Purpose & Intervention & Results \\
\hline $\begin{array}{l}\text { 1. Control to test effects of "mechani- } \\
\text { cal irritation" on brain and dura }\end{array}$ & $\begin{array}{l}\text { An unspecified number of needles were } \\
\text { "inserted at various points into dura mater } \\
\text { and brain" with no current applied }\end{array}$ & $\begin{array}{l}\text { "No results on motility or sensibility of the extremities." Raffer- } \\
\text { ty reported pain when the surface of the ulceration was } \\
\text { touched, but not when the needles were inserted into the } \\
\text { dura mater or brain }\end{array}$ \\
\hline $\begin{array}{l}\text { 2. Test of "Faradic reaction of sur- } \\
\text { face of the dura mater" }\end{array}$ & $\begin{array}{l}\text { Two needles were inserted at points described } \\
\text { as "well engaged in dura mater" first on the } \\
\text { left side and then on the right with "current } \\
\text { of least volume and intensity of one cup" } \\
\text { applied }\end{array}$ & $\begin{array}{l}\text { Deflection of the head and simultaneous contractions of the } \\
\text { upper and lower extremity on the side contralateral to the } \\
\text { hemisphere where the current was applied }\end{array}$ \\
\hline $\begin{array}{l}\text { 3. Test of "Faradic reaction of the } \\
\text { posterior lobes" }\end{array}$ & $\begin{array}{l}\text { Two needles were inserted, the first with } \\
\text { the "non-insulated portion rested entirely } \\
\text { in substance of brain" and the second in } \\
\text { contact with the dura within } 0.25 \text { inch of the } \\
\text { first needle, first on the left and then on the } \\
\text { right with presumably the same current as } \\
\text { observation } 2 \text { initially. This was repeated } \\
\text { only on the right side at a higher current "to } \\
\text { develop more decided reactions" }\end{array}$ & $\begin{array}{l}\text { Lower current caused dilation of pupils, as well as contractions } \\
\text { and significant unpleasant tingling in the contralateral upper } \\
\text { and lower extremities. Despite "very evident pain," Rafferty } \\
\text { is reported to have been smiling throughout. Higher current } \\
\text { caused "great distress" leading to Rafferty crying and an } \\
\text { epileptiform reaction characterized by loss of consciousness } \\
\text { and clonic spasms of the left arm, convulsions for approxi- } \\
\text { mately } 5 \text { minutes with frothing at the mouth and stertorous } \\
\text { breathing, followed by coma for approximately } 20 \text { minutes } \\
\text { and weakness and vertigo upon waking }\end{array}$ \\
\hline $\begin{array}{l}\text { 4. Retest of "Faradic reaction of the } \\
\text { posterior lobes" }\end{array}$ & $\begin{array}{l}\text { The same protocol as observation } 3 \text { was } \\
\text { repeated bilaterally at a decreased current } \\
\text { "not sufficient to produce epileptiform } \\
\text { attack" }\end{array}$ & $\begin{array}{l}\text { Contractions of contralateral extensor muscles with pain and } \\
\text { tingling in the extremities worse in the hands }\end{array}$ \\
\hline
\end{tabular}

between his method of stimulating the cortical surface rather than extending the needle into the brain substance and its implications for the results, but otherwise found the results in accordance with his own and concluded that the structure and function of human and animal brains were quite similar. Dupuy notably criticized the concept of Ferrier's similar study on the grounds of scientific illegitimacy ${ }^{24}$ and then Bartholow's study later. ${ }^{25}$ Although he did cede that the results of the experiment were striking, Davis did publicly and prominently support Dupuy's criticisms while addressing the 25th Annual Convention of the American Medical Association. ${ }^{22}$ The most scathing early criticism, however, came in the form of a resolution of censure that focused on ethical issues, submitted to the American Medical Association and published in the Cincinnati Medical News in $1874 .{ }^{44}$ Back and forth support and criticism of the experiment continued for some years, but eventually subsided within the medical and scientific community. ${ }^{30}$

As time went on, general opposition to the experiment fell silent in all but a few isolated cases. By the 1890 s, the principles of cortical excitability were widely accepted. ${ }^{18}$ Furthermore, Bartholow was just as widely credited with being the first to demonstrate such principles in humans. Even if he was not directly given credit for direct demonstration, few would argue his priority in proof of concept. Additionally, just as criticisms of the validity of the study dwindled, so too did the criticisms of the ethics involved. Many later reports only vaguely reported the details of the experiment that were earlier cited as cruel or focused more on the contribution to the science rather than the suffering endured by Rafferty. 45

\section{Criticisms of the Experiment}

The early criticisms of Bartholow's experiments targeted the validity of the findings and the ethics involved. Dupuy's criticisms focused on the methods of the study and the implications on the results. ${ }^{25} \mathrm{He}$ argued that because of the depth at which the needle was inserted in observations 3 and 4, any conclusions regarding cortical physiology were invalidated. The mechanism causing convulsive movements was not cortical, but the result of stimulation of white matter tracts and other deep structures. Given the information available in the report, it is impossible to know exactly what structures were stimulated. Depending on the precise location of needle insertion, depth, and conductivity of the mediums through which the current passed, there may have been cortical stimulation, subcortical stimulation, or a combination of the two. The latter possibility does appear most reasonable, considering that some current likely passed between the deeper needle and the needle placed on the dura, which must have been separated from the other by some degree of cortical tissue. It is also unclear which specific regions were responsible for the movement responses observed. If the electrodes were inserted more anteriorly, they may have stimulated neurons responsible for initiating movement within the corticospinal tract. If the electrodes were inserted more posteriorly, even though they may not have directly stimulated these neurons, they may have stimulated the neurons that provide feedback to those neurons initiating movement and caused the movements less directly. ${ }^{30}$ In any case, it is fairly unreasonable to claim that no cortical excitation occurred or contributed to the movements observed. 
Regardless of the validity of the findings, the ethical grounds on how the results were obtained were widely criticized. One notable example is the aforementioned resolution of censure. In this report, the results of Bartholow's experiment were rebuked on the grounds of ethical misconduct, and Bartholow himself was accused of "causing thereby pain, convulsions, and probably hastening death." When it was published in the Cincinnati Medical News, it was added that the experiment created a great deal of distress in the US and Great Britain. ${ }^{44}$ Beyond this publication, limited evidence of domestic disdain exists, even though it may very well have been heard at the time. However, in Great Britain, there was not a strong response, and the first reaction in the British Medical Journal withheld judgment, likely because of a letter from Bartholow that later expressed his remorse for the experiment.,31,32 In this letter he provides more information on the reasoning that led to the experiment and why he is not directly responsible for Rafferty's death, but freely admits that this information does not fully justify the experiment. Furthermore, he expresses regret for having performed the experiment, acknowledges that he did cause injury in doing so, and even states that repeating the experiment with the knowledge gained from it "would be in the highest degree criminal." Ferrier, one of the more outspoken supporters of the experiment, also recognized the danger of it and said that it was unlikely to be repeated. ${ }^{29}$ Finally, Dupuy accused Bartholow of experimenting on Rafferty because he saw her as nothing more than a worthless body, to which Bartholow assertively disagreed. ${ }^{3}$ He reaffirmed his reasoning in thinking that needle insertion would not cause further harm because of the operations Rafferty's brain had already undergone in efforts to remove pus as well as other documented cases in which the brain was penetrated with no apparent harm as a result. ${ }^{3}$ While Bartholow was far from the villain that some painted him as, he was likely not without fault prior to the experiment. It is not clear how valid Rafferty's expression of consent was, as limited evidence of the details of what she understood exists exclusively in Bartholow's report. Additionally, Ferrier's studies $^{28}$ did suggest that stimulation caused pain in animals and therefore was likely to cause pain in humans. Finally, Bartholow had originally intended to use galvanic current as well, known at the time to cause electrolytic damage. In any case, just as the discoveries from the experiment have led to modern applications, the moral circumstances have served as grounds for ethical research policies in place today.

\section{Implications}

The implications of Bartholow's study have been palpable since its publication. The most important implication of his experiment is the general acceptance of the concept of human cortical excitability. While the concept was not welcomed with open arms initially, the medical and scientific community did eventually accept it. ${ }^{18}$ In the years following the experiment, Bartholow humbly claimed priority only for the attempt at demonstration. ${ }^{5}$ However, his peers proved to be more supportive of his results, with others claiming retrospectively that he was indeed the first to demonstrate the concept, including Ojemann, a pioneer in the field..$^{40}$ The statements of first demonstration by Bartholow's peers remained even as others independently attempted experiments focused on finding proof of cortical excitability, including notable work by Sciamanna and Alberti. ${ }^{20}$ This experiment also spurred highly important debates regarding ethical dilemmas within medical research. Focuses of such debates included the necessity and practice of vivisection ${ }^{21}$ and the concept of "experimentum in corpore vili," which means "experimentation on a worthless body." ",23 The topics of these debates have evolved over the years to serve as the bases of policies used almost universally by ethical review committees to this day. One popularly reported implication of this study was that it caused Bartholow to lose his job and be chased out of Cincinnati. ${ }^{26}$ However, this claim is not supported by facts, as he did not leave Cincinnati until 1879, when he accepted a chair position at Jefferson Medical College in Philadelphia and staff position at the Philadelphia Hospital. ${ }^{19}$ If anything, it appears that the publication of his experiment did anything but hinder his productive career. , $, 8,11,13,15,17$ Finally, it has been suggested that Bartholow's experiment kickstarted the era of the surgeon experimenter, which has, in turn, led to countless medical innovations. ${ }^{38}$

\section{Conclusions}

Despite the audacious nature of the experiment with possible ethical breaches of human research, Bartholow's findings formed the foundation of the electrophysiology of the human brain. Although his methods seem crude in retrospect, they demonstrated the basic principles of human cortical mapping that are still followed in the modern era, although in a more sophisticated way. While his methods cannot be condoned, we recognize his scientific curiosity and his passion for integrating clinical medicine and experimental medicine. Just as importantly, we pay sincere tribute to the ill-fated soul, Rafferty, whose sacrifice should not be forgotten in medical history.

\section{Acknowledgments}

We would like to thank and acknowledge the US National Library of Medicine for providing public access to pictures and documents contained and referenced in this report.

\section{References}

1. Aldini G: Essai théorique et expérimental sur le galvanisme. Paris: Fournier Fils, 1804

2. Bartholow R: Cholera: Its Causes, Symptoms, Pathology and Treatment. Philadelphia: Lea, 1893

3. Bartholow R: Dr. Eugène Dupuy (Paris) on the physiology of the brain. Med Times Gaz 2:371-372, 1877 (Letter)

4. Bartholow R: The electrical room of the Good Samaritan Hospital. Clinic (Paris) 2:86-89, 1872

5. Bartholow R: Experimental investigations into the functions of the human brain. Am J Med Sci 66:305-313, 1874

6. Bartholow R: Experimental therapeutics. Introductory address. Quoted in "Medical College of Ohio." Cinci Lancet Obs 15:635-636, 1872

7. Bartholow R: Experiments on the functions of the human brain. BMJ 1:727, 1874

8. Bartholow R: A Manual of Hypodermatic Medication: 
The Treatment of Diseases by the Hypodermatic or Subcutaneous Method. Philadelphia: Lippincott, 1891

9. Bartholow R: A Manual of Hypodermic Medication: The Treatment of Diseases by the Hypodermic or Subcutaneous Method. New York: W. Wood \& Co., 1869

10. Bartholow R: A Manual of Instructions for Enlisting and Discharging Soldiers with the Medical Examination of Recruits. Philadelphia: J.P. Lippincott, 1863

11. Bartholow R: Medical Electricity: A Practical Treatise on the Applications of Electricity to Medicine and Surgery. Philadelphia: Lea, 1887

12. Bartholow R: On Spermatorrheoea: Its Causes, Symptoms, Pathology, Prognosis, Diagnosis, and Treatment. New York: W. Wood \& Co., 1866

13. Bartholow R: On the Antagonism Between Medicines and Between Remedies and Diseases: Being the Cartwright Lectures for the Year 1880. New York: D. Appleton, 1881

14. Bartholow R: A Practical Treatise on Materia Medica and Therapeutics. New York: D. Appleton, 1879

15. Bartholow R: The present state of therapeutics. Introductory Lecture, 54th session, Jefferson Medical College. Med Rec 16:337-342, 1879

16. Bartholow R: The Principles and Practice of Disinfection. Cincinnati: R.W. Carroll \& Co, 1867

17. Bartholow R: A Treatise on the Practice of Medicine: For the Use of Students and Practitioners of Medicine. New York: D. Appleton, 1887

18. British Medical Journal: Review. The Functions of the Brain. By David Ferrier, M.D., LL.D., F.R.S. BMJ 2:1104-1105, 1886

19. Butler GF: Roberts Bartholow: A great American therapeutist. A sketch of his life and a study of his work. Am J Clin Med 20:125-128, 1913

20. Casciato S, Ritaccio AL: Ezio Sciamanna: The Italian contribution to the origin of cortical stimulation mapping in humans. Epilepsy Behav 62:186-188, 2016

21. Cobbe FP: The moral aspects of vivisection. New Q Mag 4:222-237, 1875

22. Davis N: Annual address on practical medicine. Trans Am Med Assoc 25:108-120, 1874

23. Dupuy E: A critical review of the prevailing theories concerning the physiology and pathology of the brain. Med Times Gaz 2:11490, 1877

24. Dupuy E: Examen de quelques points de la physiologie du cerveau. Paris: Adrien Delahaye, 1873

25. Dupuy E: On the localisation of motor centres. Lond Med Rec 4:395-396, 1876

26. Fancher RE: Pioneers of Psychology. New York: Norton, 1996

27. Ferrier D: Bartholow's experiments on the human brain. Lond Med Rec 2:285-286, 1874

28. Ferrier D: Experimental researches in cerebral physiology and pathology. BMJ 1:457, 1873

29. Ferrier D: The Functions of the Brain. London: Smith, Elder, \& Co., 1886

30. Harris LJ, Almerigi JB: Probing the human brain with stimulating electrodes: the story of Roberts Bartholow's (1874) experiment on Mary Rafferty. Brain Cogn 70:92-115, 2009

31. Hart E (ed): Dr. Bartholow's experiments. BMJ 1:723, 1874

32. Hart E (ed): Experiments on the human subject. BMJ 1:687, 1874
33. Haymaker W, Schiller F (eds): The Founders of Neurology: One Hundred and Forty-six Biographical Sketches by Eighty-eight Authors. Springfield, IL: Charles C. Thomas, 1970

34. Hitzig E, Fritsch G: Über die elektrische Erregbarkeit des Grosshirns. Arch Anat Physiol Wissen 37:300-332, 1870

35. Holmes GL: Roberts Bartholow. In search of anatomic localization. N Y State J Med 82:238-241, 1982

36. Juettner O: Daniel Drake and His Followers. Historical and Biographical Sketches. Cincinnati: Harvey Publishing Co., 1909

37. Kelly HA, Burrage WL: American Medical Biographies. Baltimore: Norman, Remington Co., 1920

38. Krech D: Cortical localization of function, in Postman L (ed): Psychology in the Making: Histories of Selected Research Problems. New York: Knopf, 1962

39. Medical Times and Gazette: Quarterly summary of the improvements and discoveries in the medical sciences. Anatomy and physiology. 1. Functions of the brain. Am J Med Sci 67:515-517, 1874

40. Ojemann GA, Whitaker HA: Language localization and variability. Brain Lang 6:239-260, 1978

41. Ritaccio AL, Brunner P, Schalk G: Electrical stimulation mapping of the brain: basic principles and emerging alternatives. J Clin Neurophysiol 35:86-97, 2018

42. Rolando L: Saggio sopra la vera struttura del cervello dell'uomo e degl'animali e sopra le funzioni del sistema nervosa. Sassari, Italy: Nella Stamperia da SSRM Privilegiata, 1809

43. Savoy RL: History and future directions of human brain mapping and functional neuroimaging. Acta Psychol (Amst) 107:9-42, 2001

44. Thacker JA (ed): Editorial. Human vivisection. Cinci Med News 3:385, 1874

45. White JT (ed): Bartholow, Roberts, in The National Cyclopaedia of American Biography. New York: James T. White \& Co., 1932, Vol 22, pp 212-213

\section{Disclosures}

Dr. Bendok reports receiving a research grant from MicroVention.

\section{Author Contributions}

Conception and design: Bendok, Patra. Acquisition of data: Patra. Analysis and interpretation of data: Patra, Hess. Drafting the article: Patra, Hess, Abi-Aad. Critically revising the article: Bendok, Patra, Hess, Muzyka. Reviewed submitted version of manuscript: all authors. Approved the final version of the manuscript on behalf of all authors: Bendok. Administrative/technical/material support: Bendok. Study supervision: Bendok.

\section{Supplemental Information \\ Videos}

Video Abstract. https://vimeo.com/352290301.

\section{Correspondence}

Bernard R. Bendok: Mayo Clinic, Phoenix, AZ.bendok.bernard@ mayo.edu. 